\title{
International Conference in Integrative Medicine ICIM - 2020
}

\author{
Satyam Tripathi ${ }^{1 *}$, Kiran Shenoy ${ }^{1}$, Mika Azuma ${ }^{1}$, Nishant Dixit ${ }^{2}$, Sandra Thiemann-Müller ${ }^{1}$ \\ Amit Singh ${ }^{2}$, Barbara Ettenhofer ${ }^{1}$, Aw Mayling ${ }^{1}$, Jjoyce Chong ${ }^{1}$, Prashant Kumar Singh ${ }^{1}$, \\ Gairola Ganesh Prasad ${ }^{1}$, Parnella Rayappan ${ }^{1}$, Megha Panchal ${ }^{1}$
}

Union Yoga Ayurveda, Singapore ${ }^{1}$

Arogyadhama, SVYASA University, Bengaluru²

*Corresponding Author:

Satyam Tripathi, MD

Union Yoga Aurveda, Singapore

Contact no: $+65-832166170$

E-mail: ayur.st@gmail.com

\section{Introduction}

International Conference Integrative Medicine - 2020 was organised from September 04 to 06,2020 by Union Yoga Ayurveda (Singapore) and Central Council of Research in Yoga and Naturopathy (India). The theme of this conference was "Challenges and Opportunities for Integrated Remedies for Cancer". Integrative remedies is an inclusive approach of practicing medicine in a way that selectively incorporates elements of alternative medicine into comprehensive treatment. It can help people with communicable and noncommunicable diseases such as cancer, $(1,2)$ persistent pain, (3) diabetes management (4) and many other conditions to manage their symptoms and improve their quality of life. Integrative medicine has healing-oriented approach that can give a wider and wholesome perspective towards the disease and its relation to human body. Another role of integrative medicine is preventing future health issues before they arise and setting the foundation for overall positive health. ICIM welcomed distinguished experts from various streams of healthcare in this conference and shared their experience and understanding as per their respective system of medicine under one roof.

This conference offers a great platform to assemble an international community of modern medicine, integrative medicine and holistic scientists to come together to find out what best we can do for the cure and management of cancer.

\section{Conference Planning}

This conference was been planned in 3 levels.

- Level 1: Working with Cancer patients who were undergoing conventional treatment were taught yoga protocols by yoga trainers. These protocols were planned by Union Yoga Ayurveda Singapore based on scientific research. Cancer clients were given the intervention to check the immediate effect and the feedback was collected.

- Level 2: The conference welcomed different scientists from all over the world who are working in holistic and integrative medicine to send their research work in the form of abstract to compile into a souvenir booklet.

- Level 3: Building a platform to bring this panel of doctors and masters to discuss and pave the way for what should be done next to make it as an international standard medicine and education, where the international standard setters from IAYT and Maryland University of Integrative Health, were also welcomed.

Conference started on $4^{\text {th }}$ Sepember 2020 at Singapore Standard Time (SST- GMT+8hrs) 6:00pm with a Yin yoga practice session by Master Victor Chng after which Dr. BR Ramakrishna addressed the gathering over the "Effects of Integrative Medicine on Side effects of Cancer and its Management" in which he explained the limitation of practicing a single system of medicine and how integrative approach can serve the mankind. His session was followed by two more sessions "Ayurveda for Preventive and Palliative Care in Gynae Oncology" and "Ayurveda in the management of side effects of Cancer - Perspectives and Evidence" by Dr. Shreyes S of RGES Ayurvedic Medical College, Ron, Karnataka and Dr. Sriranjini Jaideep from the Dept of Neurophysiology, NIMHANS, Bangalore, who enlightened the audience about the Ayurvedic understanding about the Cancer and how Ayurveda can help in thr prevention and Management of Cancer. She also mentioned about some of the clinical trials done on the Ayurvedic herbs such as Ashwagandha (5) (Withania Somnifera) and Triphala (6) which proved to be very effective in improving the lifestyle of Cancer patients.

The $2^{\text {nd }}$ day of the conference which was $05^{\text {th }}$ September 2020 started with talks of Ms Diane Finlayson from Maryland University of Integrative Health. She explained about the need for learning standards as per Yoga Ayurveda Certification. Dr. Diane explained about the accreditation process of Yoga and Ayurveda professionals. She also emphasized the need for the Yoga and Ayurveda professionals to follow the accreditation process to get integrated with conventional medicine.

Dr. Sat Bir Khalsa, from Harvard Medical School, USA talked about the the topic "Yoga for Cancer Patients: A Scientific Rationale and Review of Research Evidence" where he 
explained explained how various research paper show that Yogic Practices have a deep impact from body to the very subtler levels of our being. Dr. Khalsa summarized his session with the discussion on how yoga research has become popular for cancer because there are no successful treatment is available for these patients. He cited a few research papers from cancer studies to specific type of cancer such as "Yoga for Symptoms management in Oncology" a Randomized control trial done on the participants during cancer, post cancer and with mixed samples. The results of this study showed that fatigue was the most commonly measured outcome, and RCTs conducted during or after cancer treatment reported improvements in fatigue. Results also suggest that yoga can improve stress / distress during treatment and post treatment disturbances in sleep and cognition. At last, Dr. Khalsa dwellad on a very significant point that how yoga can be a very cost effective approach to improve quality of life in cancer patients.

Dr. Karen M Mustian from University of Rochester Cancer Center addressed the gathering by speaking on "Is Chemotherapy \& Radiotherapy Useful in Stage 3 \& Stage 4? How can Integrative Medicine compliment?" in which they summarized that yogic intervention can help improve certain aspects of the quality of life in cancer patient such as sleep, anxiety, mood etc.

Dr. Meenakshi from Central University of Rajasthan spoke about her research work "Symptom Burden and Quality of Life Impairment in Head \& Neck Cancer patients undergoing radiotherapy and its relationship with perceptions of Yoga Intervention". This study was conducted in Health Care Global Enterprise, Bangalore. In this study she finds that those cancer patients who are performing yoga have significant lower amount of distress in comparison to those who are not doing Yoga in their routine. She concludes in her study that adding yoga to the conventional treatment can prove to be an important and useful adjunct.

A very comprehensive panel discussion on Ayurveda for Cancer took place on $6^{\text {th }}$ September 2020. The panel consisted of internationally known specialists of Ayurveda, Ms Diane Finlayson, Dr. Vaidya Balendu Prakash, Vd. K. S. Dhiman, Dr. Sriranjini Jaideep, Dr. Patil Nitin J, Dr. Ahalya Sharma, Mr. John Kepner and the discussion was moderated by Dr. Satyam Tripathi.

Dr. Satyam Tripathi gave the note of thanks on $6^{\text {th }}$ September in the evening and stated that the work in integrative medicine will be a way forward for the future healthcare.

More than 800 people from various countries registered themselves for this conference. The delegates were mainly from Singapore, Germany, India, Russia, Denmark and Switzerland. An Yoga Intervention for cancer patients were also organized in which 41 cancer patients (21 Breast, 2 Throat, and 18 others).

Three protocols were prepared to conduct sessions. As a result, each protocol was almost equally conducted. $15 \%$ of the session needed modification based on the protocols by teachers. As mentioned earlier, patients' condition changes day

\section{Patient's nationalities}

\begin{tabular}{|c|c|}
\hline Nationality & Number of patients \\
\hline Singaporean & 20 \\
\hline German & 13 \\
\hline Indian & 3 \\
\hline Russian & 1 \\
\hline Dutch & 1 \\
\hline Swiss & 1 \\
\hline
\end{tabular}

to day. Therefore even though $67 \%$ of patients are in remission, some of them prefer to choose protocol with MSRT (Mind Sound Resonance Technique).

\section{Type of Protocol}

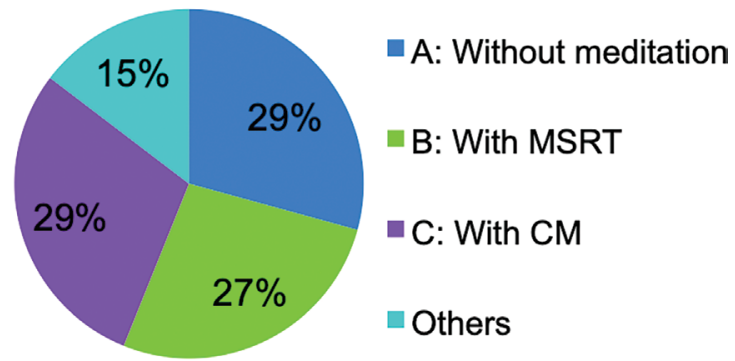

\begin{tabular}{|c|c|}
\hline Type of protocol & Number of patients \\
\hline Without meditation & 12 \\
\hline With MSRT & 11 \\
\hline With CM & 12 \\
\hline Others & 6 \\
\hline
\end{tabular}

Total 40 yoga teachers were trained for this awareness program and 18 teachers had sessions with cancer patients. The majority of teachers' nationality is Singapore and others were Indian, Russia, Netherlands, Filipino, Swiss, Polish, Malaysian, UK, and German and sessions were conducted in different languages.

\section{Yoga teachers' nationalities}

\begin{tabular}{|c|c|}
\hline Nationality & Number of teacher \\
\hline Singaporean & 24 \\
\hline Indian & 6 \\
\hline Russian & 2 \\
\hline Swiss & 2 \\
\hline Others & 6 \\
\hline
\end{tabular}

doi: 10.38205/imcr.020104 